\title{
Assessing the Vulnerability of Groundwater to Pollution Using DRASTIC and VLDA Modelsin Halabja Saidsadiq Basin, NE, Iraq
}

\author{
Twana O. Abdullah ${ }^{1,3}$, Salahalddin S. Ali ${ }^{2}$, Nadhir A. Al-Ansari ${ }^{3}$ and Sven Knutsson ${ }^{3}$ \\ 1. Department of Geology, University of Sulaimani, Kurdistan Region 46001, Iraq \\ 2. University of Sulaimani, Kurdistan Region 46001, Iraq \\ 3. Department of Civil, Environmental and Natural Resources and Engineering, Division of Mining and Geotechnical Engineering, \\ Lulea University of Technology, Lulea 97187, Sweden
}

\begin{abstract}
Groundwater plays important roles as one of the essential source of water supplies of the studied area. Consequently, it needs to be prevented from contamination. In this study, two methods have been examined, namely DRASTIC (depth to groundwater, net recharge, aquifer media, soil map, topography, impact of vadose zone and hydraulic conductivity) and VLDA (vadose zone lithology, land use patterns, depth to groundwater and aquifer media) to model a map of groundwater vulnerability for contamination of the basin. The standard DRASTIC vulnerability maps classified the basin of four vulnerability index zones: very low (34\%), low $(13 \%)$, moderate $(48 \%)$ and high $(5 \%)$. While the VLDA model classified the area into four categories as well: low (2\%), moderate $(44 \%)$, high (53\%) and very high (1\%). The results demonstrate that there is a significant dissimilarity in the rate of vulnerability. Validation of the constructed maps is required to confirm the validity of the theoretical sympathetic of current hydrogeological conditions. In this study, nitrate concentration analysis was selected as a contamination indicator to validate the result. The nitrate concentration of two different seasons (dry and wet) was analyzed from (30) watering wells, considerable variations in nitrate concentration from dry to wet seasons had been noted. Consequently, it points toward that groundwater in the HSB (Halabja Saidsadiq Basin) is capable to receive the contaminant due to suitability of overlies strata in terms of geological and hydrogeological conditions. Based on this confirmation, the result exemplifies that the degree and distribution of vulnerability level acquired using VLDA model is more sensible than that attained from the standard DRASTIC method .In addition, the DRASTIC models need to be modified based on the land use pattern, which clarifies the role of human activity on the vulnerability system.
\end{abstract}

Key words: Vulnerability, DRASTIC, VLDA, nitrate concentration, Halabja Saidsadiq Basin.

\section{Introduction}

Groundwater is a fundamental water source of various region in the world. Halabja and Saidsadiq area which is located in the northeastern part of Iraq (Fig. 1) is one of actual example as a source for drinking, industrial and agricultural activities. Several thousand deep wells exits from the studied area based on the data obtained from the Directorate of Groundwater in Sulaimani City. As a consequence, the study of the groundwater resources and its potential pollution in the area becomes inevitability.

Corresponding author: Nadhir A. Al-Ansari, professor, research fields: water resources and environmental engineering.
To do this, there are classical scientific [1] and numerical methods [2, 3], to clarify the identification of the groundwater condition and to resist the pollutants in the reservoirs such as DRASTIC (depth to groundwater, net recharge, aquifer media, soil map, topography, impact of vadose zone and hydraulic conductivity), VLDA (vadose zone lithology, land use patterns, depth to groundwater and aquifer media), COP (concentration of flow, overlying layer and precipitation), GOD (groundwater occurrence, overall aquifer class and depth of groundwater table), SINTACS (depth to water, infiltration, vadose zone, overburden typology, aquifer, hydraulic conductivity 
and surface slope), etc. These different methods are offered under the form of numerical excerpt systems based on the negotiation of the different factors affecting the hydrogeological system [4]. In HSB (Halabja Saidsadiq Basin), DRASTIC method was applied previously by Abdullah et al. [5]; while it is very important to know that this model is reflecting the actual vulnerability system for this specific area. So, the main objective of the current study is to compare DRASTIC method of one more recommended model. VLDA model beside DRASTIC model was selected, because these two models can be applied for the region in terms of aquifer properties. In addition, both models are using different rates and weight value of the applied parameters and different potential characteristic on vulnerability system such as aquifer properties, unsaturated zone, etc. And then, the results have to be validated. For the validation purpose, nitrate concentration on groundwater was used, because this region is an arable area because of its suitability for agriculture. Accordingly, the employments of fertilizers and pesticides are normal practices, so it influences the groundwater quality [6]. Normally, different types of inorganic chemical fertilizer were used in the studied area namely sodium nitrate and chemical compounds that contain nitrogen in amide form [7].

\section{Study Area}

Geographically, the study area is located in the northeastern part of Iraq between the latitude $35^{\circ} 00^{\prime} 00^{\prime \prime} \mathrm{N}$ and $35^{\circ} 36^{\prime} 00^{\prime \prime} \mathrm{N}$ and the longitude $45^{\circ} 36^{\prime} 00^{\prime \prime} \mathrm{E}$ and $46^{\circ} 12^{\prime} 00^{\prime \prime} \mathrm{E}$ (Fig. 1). This basin is divided into two sub-basins including Halabja-Khurmal and Said Sadiq sub-basins [8]. The total area of both sub-basins are about $1,278 \mathrm{~km}^{2}$ with population of about 190,727 in early 2015 according to the data achieved from Statistical Directorate in Sulaimaniyah. This area is characterized by a distinct continental interior climate of hot summers and cold

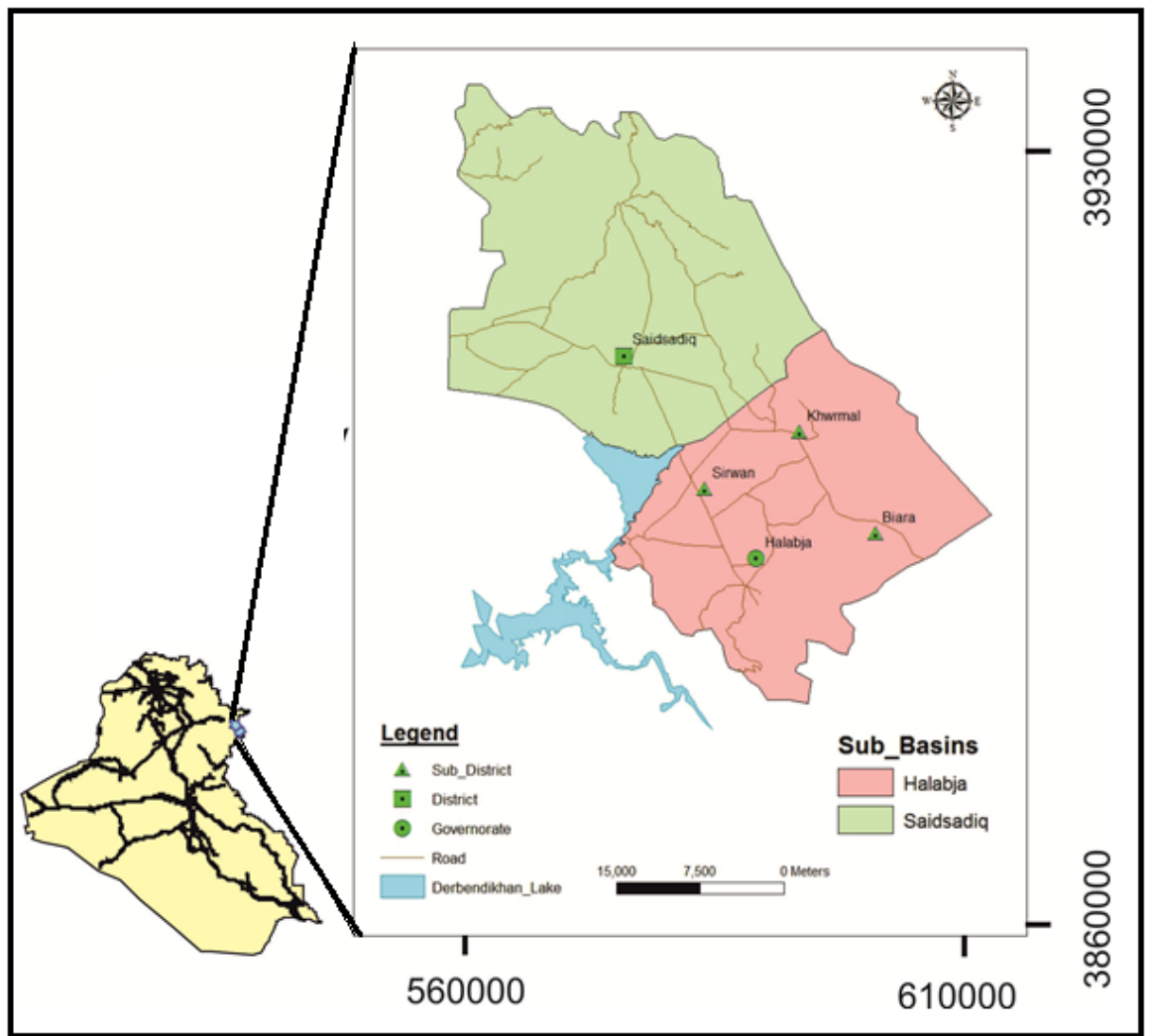

Fig. 1 Location map of the study area. 
winters of the Mediterranean type with the average annual precipitation ranging from $500 \mathrm{~mm}$ to $700 \mathrm{~mm}$. Approximately, $57 \%$ of the studied area is an arable area due to its suitability for agriculture. Consequently, the use of fertilizers and pesticides are common practices, so it affects the groundwater quality [6]. In addition, all of the municipal wastewater from the cities of Halabja and Saidsadiq and all other sub-district sites within this basin infiltrate into the groundwater every year.

\subsection{Geology and Hydrogeological Setting}

Geologically, as mentioned by Buday and Jassim [9], HSB is situated inside the Western Zagros Fold-Thrust Belt. While in terms of structural geology, it is located inside the high folded zone, imbricated, and thrust zones [10]. Different geological formations were deposited in the area with geological age ranging from Jurassic to recent [11].

Permeability is the primary foremost factor of deciding the capability of the area to be considered as a water bearing aquifer. The area is portrayed by several distinctive hydrogeological aquifers because of vicinity of various geological units. The trademark components of the aquifers are classified in Table 1. From the gathered field information and those recorded in the chronicles of the Groundwater Directorate in Sulaimaniyah, the mountain arrangement encompassing the basin of the upper east and southeast, is portrayed by high profundity of groundwater. In the middle and the southeastern part, the groundwater level has a moderately bring down profundity. The movement towards groundwater is for the most part of high raised territories in the north and upper east and south and southeast towards southwest or for the most part toward the repository of Derbandikhan Dam.

Moreover, few streams exist in the region, for example, Sirwan, Zalm, Chaqan, Biara, Reshen and Zmkan. Every one of these streams appropriates their water in Derbandikhan supply. There are a few springs inside the basin [5]. These springs can be arranged into three classes as indicated by their water release. The main group having discharged that is under $10 \mathrm{~L} / \mathrm{s}$, (for example, Anab, Basak, Bawakochak and 30 different springs). The second group having discharged of $10 \mathrm{~L} / \mathrm{s}$ to $100 \mathrm{~L} / \mathrm{s}$, (for example, Sheramar, Qwmash, Khwrmal and Kani Saraw), lastly, those have water discharge more than 100 L/s (for example, Garaw, Ganjan, Reshen, Sarawy Swbhan Agha).

\section{Methodology}

\subsection{Material and Source of Data}

The required information about this assessment was gathered from the field and afterward from the records of the related association, for example, groundwater directorate in Sulaimaniyah City. Arc Map 10 programming was utilized to make the shape file of every layer. Nitrate concentration investigation used to confirm the proposed applied models.

\subsection{Standard DRASTIC Model}

The most suitable, practical and generally exploited model to assess groundwater vulnerability to a widespread

Table 1 Type of aquifers in the study basin.

\begin{tabular}{|c|c|c|c|}
\hline Aquifer & Formation & Thickness (m) & References \\
\hline Intergranular aquifer & Quaternary deposits & more than 300 & {$[12]$} \\
\hline Fissured aquifer & $\begin{array}{l}\text { Balambo } \\
\text { Kometan }\end{array}$ & 250 & {$[8]$} \\
\hline Fissured-karstic aquifer & $\begin{array}{l}\text { Avroman } \\
\text { Jurassic formation }\end{array}$ & $\begin{array}{l}200 \\
\text { From } 80 \text { to } 200\end{array}$ & {$[13]$} \\
\hline Non-aquifer (aquitard) & $\begin{array}{l}\text { Qulqula } \\
\text { Shiranish } \\
\text { Tanjero }\end{array}$ & $\begin{array}{l}\text { More than } 500 \\
225 \\
2,000\end{array}$ & {$[13]$} \\
\hline
\end{tabular}


range of potential contaminants is DRASTIC model. This model was created by EPA (Environmental Protection Agency) of the United States to sort out the contamination capability of aquifers [14]. DRASTIC model for the first time was applied for HSB by Abdullah et al. [11], so the final outcome of this model is utilized to compare it with the VLDA model.

\subsection{VLDA Index Model}

On the basis of the DRASTIC model for assessing groundwater vulnerability and in accordance with certain principle, VLDA model is proposed by Zhou et al. [15]. VLDA principally reflects the lithology on vadose zone $(V)$, signifying soil media and impact on vadose zone in DRASTIC model. This parameter controls various physicochemical processes of infiltration waters in vadose zone. The second parameter is the pattern of land use $(L)$, demonstrating two indexes of DRASTIC model, including net recharge of aquifer and topography, which reflects the amount and process of water consumption or discharge of unit area, as well as types, sources and quantity of pollutants. Groundwater depth $(D)$, which determines contact time of pollutants with vadose zone media. The fourth parameter in VLDA model is aquifer characteristics $(A)$, representing aquifer media and hydraulic conductivity, which greatly affect the infiltration route of pollutants after the pollutants enter the aquifer. Therefore, VLDA model is established based on these four indexes for evaluating groundwater vulnerability. In addition, consistent weight can be assigned to each of the four indexes depending on its impact on groundwater vulnerability. Based on the principles of universality, intelligibility and readability [15], the inclusive assessment method is used in this study to assess groundwater vulnerability of HSB. The vulnerability comprehensive assessment index $(D I)$ is the weighted sum of the abovementioned four indexes, as computed conferring to the following equation [15]:

$$
D I=\sum_{j=1}^{4}\left(W_{i j} R_{i j}\right)
$$

where, $D I$ is the comprehensive assessment index of the $i$ th sub-system of the groundwater vulnerability system in the HSB; $W_{i j}$ is the weight of the $j$ th comprehensive assessment index of the ith sub-system, and $\sum_{j=1}^{4} W_{i j}=1 ; R_{i j}$ is the value of the $j$ th assessment index of the $i$ th subsystem; 4 is the quantity of indexes.

The slighter the DI signifier to the lower vulnerability of the groundwater system, the better the stability will be. Quite the reverse, the bigger the $D I$ is the higher, the vulnerability of the groundwater system and the poorer the stability will be.

\subsubsection{Weight Determination}

For evaluating the groundwater vulnerability, different weights were proposed by different researchers. For instance, in applying DRASTIC model, Aller et al. [14] assigned the weight (5, 4, 3, 2, 1, 5 and 3) to the depth of groundwater, net recharge, aquifer media, soil media, topography, impact on vadose zone and hydraulic conductivity, respectively. Correspondingly, the weight of $V, L, D$ and $A$ in VLDA model as proposed by Zhou [16] is 7, 5, 5 and 6 , respectively, and after normalization, the weight is $0.304,0.217,0.217$ and 0.261 , respectively.

When using DRASTIC model, for the same set of indexes mentioned above, Ibe [17] provided the following weights: $5,3,3,2,1,5,4$ and the corresponding weight of VLDA model is $7,4,5,7$, or $0.304,0.174,0.217,0.304$, respectively, after normalization. Dixon [18] contributed the following weights: $5,4,3,5,3,4,2$, and the corresponding weight of $V, L, D, A$ in VLDA model is $9,7,5,5$, or $0.346,0.269,0.192,0.192$, respectively, after normalization. Bukowski, Bromek and Augustyniak [19] gave weights: $3,4,4,4.5,2,4.5$ and 2.5, therefore, the corresponding weight of $V, L, D, A$ in VLDA model is $8.5,6,3,6.5$, or $0.354,0.250,0.125$, 0.271 , respectively, after normalization.

In using the DRASTIC model, Panagopoulos, 
Antonakos and Lambrakis [20] set the weights of groundwater depth, net recharge, aquifer types, topography, vadose zone as $3,1,5,2,2.5$, respectively, and the corresponding weight of $V, L, D, A$ in VLDA model is $2.5,3,3,5$, or $0.185,0.222,0.222,0.370$, respectively, after normalization.

In addition, the weight of groundwater depth, net recharges of aquifer, aquifer medium, soil and land uses and coverage, topography, hydraulic conductivity as $5,4,3,3,3,2$, respectively, was proposed by Nobre et al. [21], and the corresponding weight of $V, L, D, A$ in VLDA model is $3,7,5,5$, or $0.150,0.350,0.250$, 0.250 , respectively, after normalization.

In applying DRASTIC model, Kourosh, Ramin and Vahid [22] set the normalized mean effective weight for groundwater depth, net recharge of aquifer, aquifer medium, soil medium, topography, vadose zone and hydraulic conductivity as $0.130,0.203,0.096,0.121$, $0.099, \quad 0.213$, and 0.138 , respectively. Correspondingly, the weight of $V, L, D$, A in VLDA model is $0.334,0.302,0.130,0.234$, respectively. In addition, Zhou [16] proposed the normalized weights from the average of the above mentioned value of weights or $0.312,0.227,0.177$ and 0.284 , respectively for VLDA.

As a result, on the basis of the arithmetic averages from previously applied normalized weights, the weight value for VLDA proposed to be is $0.286,0.251$, 0.191 and 0.271 , respectively $[12,23]$. While for this study, the new corresponding weights of DRASTIC model in HSB were proposed using sensitivity analysis method. As illustrated by Babiker et al. [24], the weights used to calculate the vulnerability index might change based on the different geological and hydrogeological conditions of the study area. Sensitivity analysis evaluates the effective weights of each parameter.

The effective weight is the function of the value of a single parameter as well as the weight assigned to it by the DRASTIC model [24]. The impact on each parameter in the index computation was assessed by achieving a sensitivity analysis. Eq. (7) was used to calculate the effective weight of each parameter [25].

$$
W=\left(\frac{\operatorname{Pr} P w}{v}\right) * 100
$$

where, $W$ is the effective weight of each parameter, $P r$ is the rating value and $P w$ is the weight value of each parameter, and $v$ is the overall vulnerability index.

According to the result of sensitivity analysis, the proposed weights used for DRASTIC indexes in HSB were $5.2,3.8,3.4,2.6,1,5.6$ and 1.4 , respectively. Congruently, the weight of VLDA model measured as 8.2, 4.8, 5.2 and 4.8, and after normalization, the weight is $0.357,0.209,0.226$ and 0.209 , respectively (Table 2).

\section{Result and Discussion}

\subsection{Assessment of Standard DRASTIC Model}

Fig. 2 shows the standard DRASTIC vulnerability model of HSB with four vulnerability classes. These are: very low, low, moderate and high vulnerability index. The map obviously illustrates the dominance of moderate and very low vulnerability zones which cover an area of $614 \mathrm{~km}^{2}$ and $435 \mathrm{~km}^{2}$ or $(48 \%$ and $34 \%$ ) of the whole studied area, respectively. In terms of the geological and hydrogeological conditions, moderate vulnerability zone occupies two different areas. The first one is the mountains surrounding the studied basin that includes the fissured and karstic aquifer. While the second area comprises the Quaternary

Table 2 Weights of indexes in VLDA model.

\begin{tabular}{lllll}
\hline Calculation of indexes & $\begin{array}{l}\text { Lithology of vadose } \\
\text { zone }(V)\end{array}$ & Pattern of land use $(L)$ & Groundwater depth $(D)$ & Aquifer characteristics $(A)$ \\
\hline $\begin{array}{l}\text { Weights (sensitivity } \\
\text { analysis) }\end{array}$ & 0.357 & 0.209 & 0.226 & 0.209 \\
$\begin{array}{l}\text { Weights (previously } \\
\text { proposed) }\end{array}$ & 0.286 & 0.251 & 0.191 & 0.271 \\
\hline
\end{tabular}




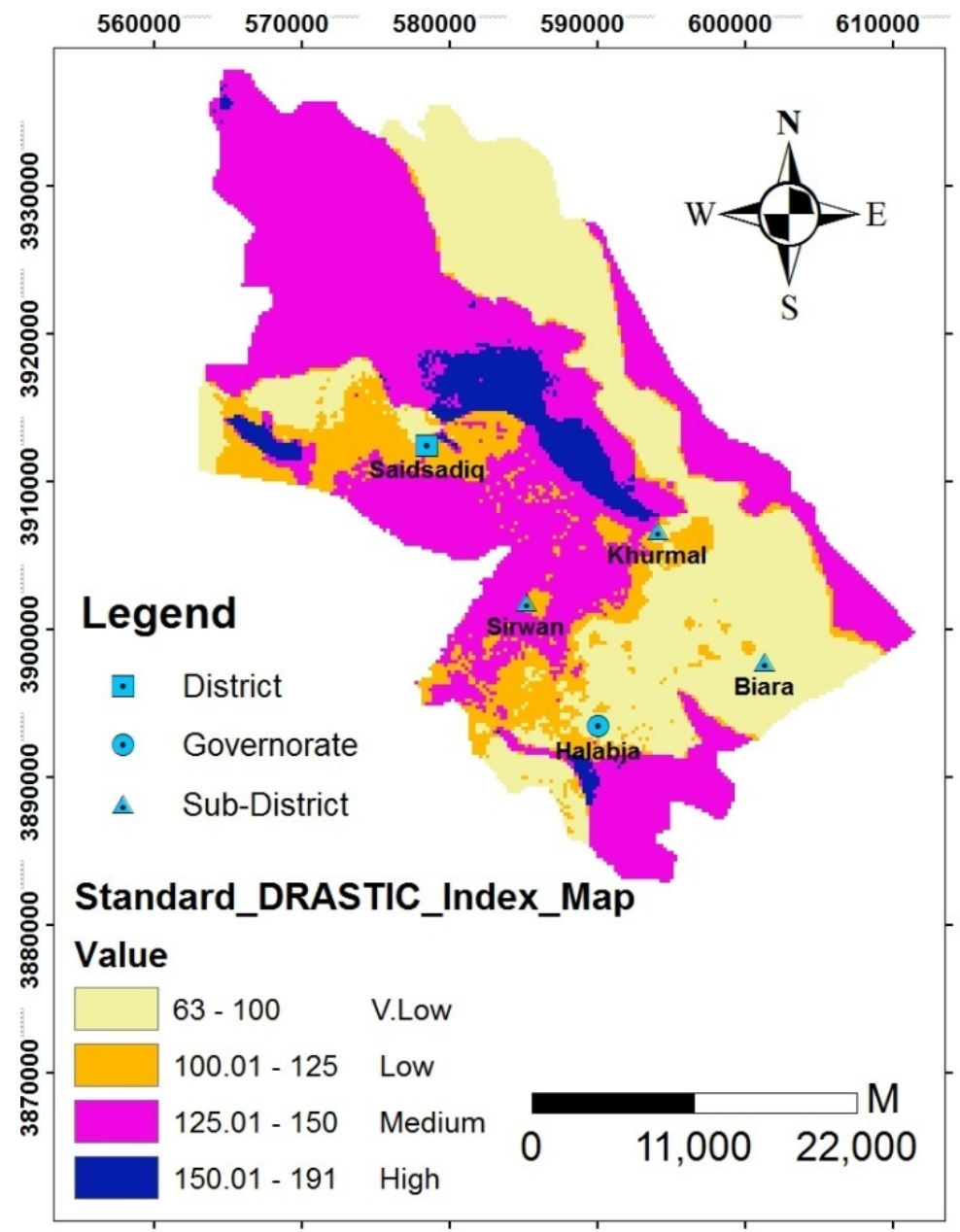

Fig. 2 Standard DRASTIC map for HSB.

deposits surrounding the area of Derbandikhan reservoir of the southwest of the basin, this might be related to the high water tables level and high percent of coarse grain material such as gravel, sand and rock fragment. Furthermore, the zone with low vulnerability is considered as the third class in terms of spreading and occupy $166 \mathrm{~km}^{2}$ or $13 \%$ of the overall surface area of the basin. The zone with high vulnerability indexes covers only $64 \mathrm{~km}^{2}$ or $5 \%$ of the total area and is located in the center of the basin. This area is characterized by high water table level and presence of several springs with fractured limestone.

\subsection{Assessment of VLDA Model}

4.2.1 Lithology of Vadose Zone (V)

Lithology of vadose zone controls various physicochemical processes of seepage water in the vadose zone. The finest particles of the medium are, the smaller quantity of contaminants reaching aquifer will be, therefore the lowering the possibility of vulnerability of groundwater.

According to the geological map of HSB [11] and based on the stratigraphic profile of the drilled wells in the basin, highly fissured limestone, non-fractured cherty limestone, silt, marl and mixture of gravel, sand and clay are the major ingredients incorporated in the media of vadose zone of for HSB. According to the scoring principle of VLDA model (Table 3), vulnerability scores of lithology of vadose zone in the area are set between 3 and 10, and the weighted scores are between 1,071 and 3.57, as shown in Table 3 and Fig. 3. 
Table 3 Weighted scores of lithology of vadose zone $(V)$.

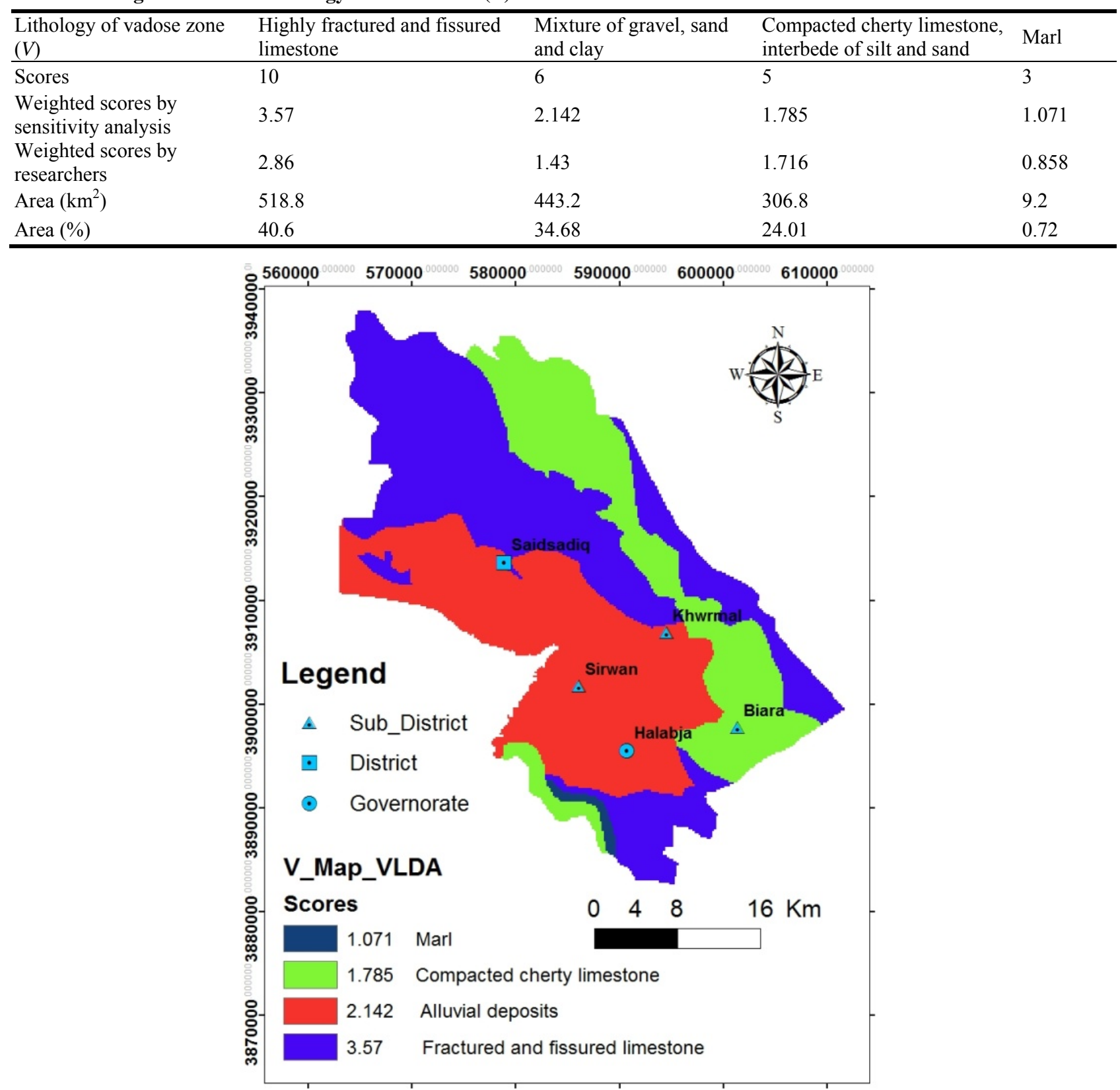

Fig. 3 Weighted scores of lithology of vadose zone $(V)$.

\subsubsection{Pattern of Land Use $(L)$}

Pattern of land use $(L)$ defines water utilization or discharge in addition to the types of pollution sources and quantity of pollutants. In urban area, the possibility for waste (dirty) waters entering groundwater is comparatively high. Thus, the groundwater is relatively vulnerable; in normal farmland, wet land and agricultural area pollutants may enter the groundwater. Thus, the vulnerability of the groundwater is at a moderate level; in barren land and natural vegetation area, no artificial pollutant enters the groundwater. Thus, the groundwater has a relatively low vulnerability.

The land uses map of HSB constructed based on the interpretation of two different scenes of Landsat Thematic Mapper (TM), date back from March 5, 


\section{Assessing the Vulnerability of Groundwater to Pollution Using DRASTIC and VLDA Models in Halabja Saidsadiq Basin, NE, Iraq}

2010 using remote sensing technique. In addition, the satellite images classified were based on the USGS (United State Geological Survey) system that developed by Anderson et al. [26]. ERDAS IMAGINE software was used to prepare digital image classification of the study basin. Supervise classification for Level I of USGS with band combination $\mathrm{RGB} / 742$ was applied to analysis all satellite images that covered the study basin. The study area is extracting from the results map of classification according to the catchment area of HSB using ArcGIS software. The analyses are supported by field works, many points taken with GPS and several photos were taken as well to check the accuracy and validity of the final map of classification. The map demonstrates that the area of HSB is divided into five classes based on their different uses: urban land, agricultural land, barren land, vegetation and water or wet land (Fig. 4).

In compliance with the scoring principle of VLDA model, scores of land use in the area of HSB ranged from 3 to 8 , and the weighted scores ranged from 0.627 to 1.672 from the weight calculated based on sensitivity analysis (Table 4 and Fig. 4).

\subsubsection{Groundwater Depth $(D)$}

The depth of groundwater is described as the distance from unsaturated zone that pollutant desires to travel through to reach the water table. For the present study, groundwater level was measured and documented in about 1,200 wells. Water table measurements were taken in May and early June because these months are considered as the potential worst-case scenario due to the low depth of groundwater. The IDW (inverse distance weighted) was

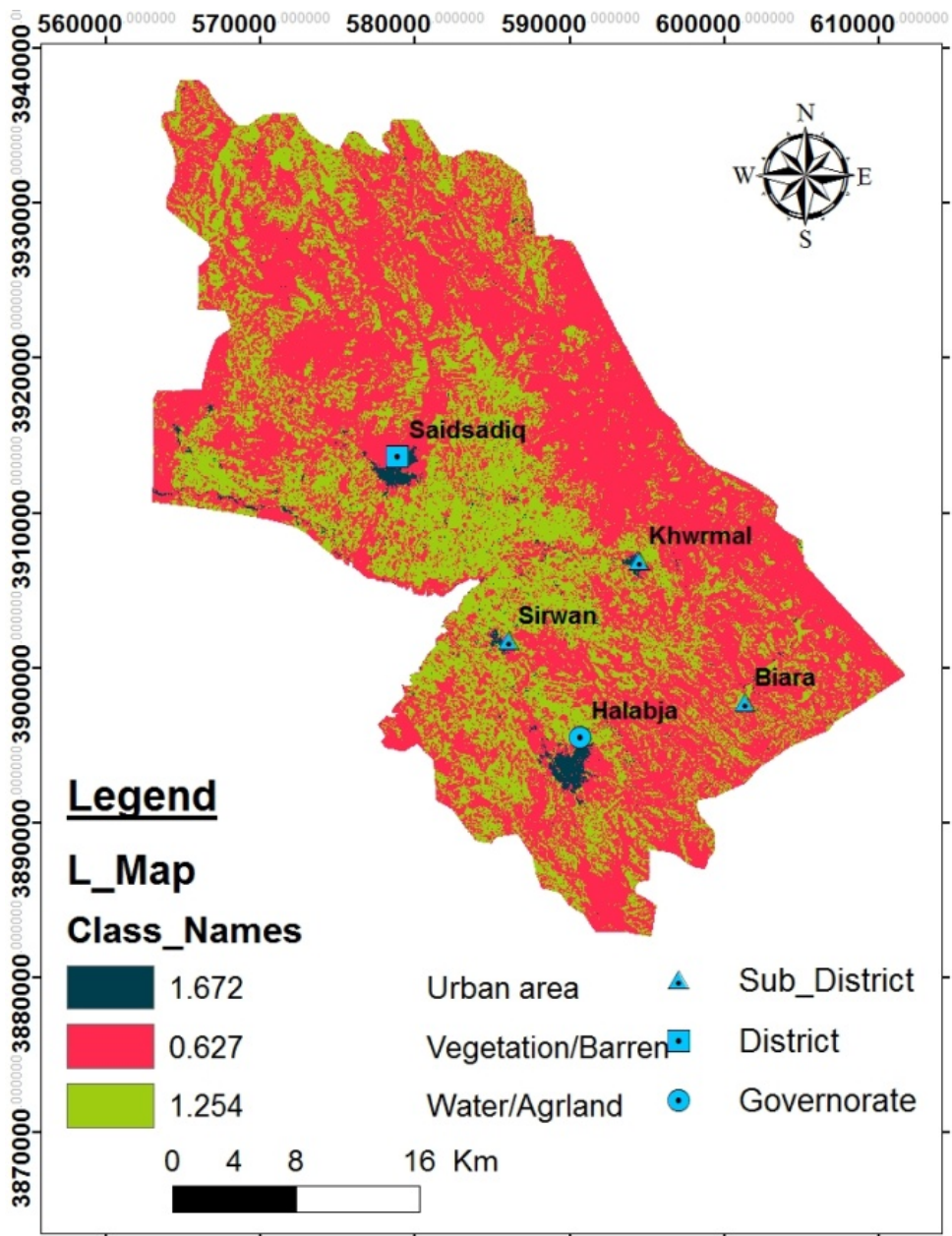

Fig. 4 Weighted scores of pattern of land use $(L)$. 
Table 4 Weighted scores of pattern of land use $(L)$.

\begin{tabular}{llll}
\hline Pattern of land use & Urban area & Agricultural and water or wet land & Barren land and vegetation \\
\hline Scores & 8 & 6 & 3 \\
Weighted scores by sensitivity analysis & 1.672 & 1.254 & 0.627 \\
Weighted scores by researchers & 2.008 & 1.506 & 0.753 \\
Area $\left(\mathrm{km}^{2}\right)$ & 17 & 455 & 806 \\
Area $(\%)$ & 1.3 & 35.6 & 63.1 \\
\hline
\end{tabular}

Table 5 Weighted scores of groundwater depth $(D)$.

\begin{tabular}{lllll}
\hline Groundwater depth $(D)$ & Scores & Weighted scores by sensitivity analysis & Weighted scores by researchers & Area $\left(\mathrm{km}^{2}\right)$ \\
\hline $0 \sim 1.5$ & 10 & 2.26 & 1.91 & $97.5(7.6 \%)$ \\
$>1.5 \sim 4.5$ & 9 & 2.034 & 1.719 & $93.3(7.3 \%)$ \\
$>4.5 \sim 7.5$ & 8 & 1.808 & 1.528 & $48.8(3.8 \%)$ \\
$>7.5 \sim 10$ & 7 & 1.582 & 1.337 & $22.7(1.8 \%)$ \\
$>10 \sim 12.5$ & 6 & 1.356 & 1.146 & $28.8(2.3 \%)$ \\
$>12.5 \sim 15$ & 5 & 1.13 & 0.955 & $35.2(2.8 \%)$ \\
$>15 \sim 19$ & 4 & 0.904 & 0.764 & $57.7(4.5 \%)$ \\
$>19 \sim 23$ & 3 & 0.678 & 0.573 & $55.8(4.4 \%)$ \\
$>23 \sim 30$ & 2 & 0.452 & 0.382 & $118.6(56.3 \%)$ \\
$>30$ & 1 & 0.226 & 0.191 & $719.6(9.3 \%)$ \\
\hline
\end{tabular}

used to interpolate the data to construct the depth to water table layer as a raster format and then reclassified based on the ranges and rating recommended by Zhou [16]. In HSB, the depth of groundwater varies from 0 to more than $100 \mathrm{~m}$. Therefore, 10 classes were used for the studied basin. These are $0 \sim 1.5,1.5 \sim 4.5,4.5 \sim 7.5,7.5 \sim 10,10 \sim 12.5$, $12.5 \sim 15,15 \sim 23,23 \sim 30$ and more than $30 \mathrm{~m}$. In obedience with the scoring standard of VLDA model, scores of groundwater depth range from 1 to 10 , and the weighted scores range from 0.226 to 2.26 (Table 5 and Fig. 5).

\subsubsection{Aquifer Characteristics $(A)$}

Flow system of groundwater regulates the transmission path of the pollutants and length of the route, while aquifer characteristics (i.e., type of aquifer and hydraulic conductivity or water yield property of aquifer) have reflective influence on groundwater leakage path. The hydraulic conductivity $(C)$ describes the ability of the aquifer material to transmit water through it and contaminant migration is controlled by the permeability of the media [27]. The hydraulic conductivity map was constructed by employing the pumping test analysis results as mentioned previously with using Eq. (6). In addition, the average of yield of each aquifer was computed based on the discharge of about 100 watering wells. According to the hydraulic conductivity and yield of water wells in HSB, water yields property of aquifers in the HSB were classified and divided into five grades in high rich storage zone to limited rich storage zone (Table 6). In acquiescence with scoring principle of VLDA model, scores of aquifer characteristics of HSB are set between 1 to 9 , and the weighted scores are between 0.209 to 1.881 (Fig. 6).

\subsubsection{Assessment of VLDA model}

After the weighted scores were attained for the four indexes required in the VLDA model, the weights were used in this study calculated based on the sensitivity analysis method. The GIS technique was used to combine the four scores and to classify the area of HSB in terms of vulnerability zoning as well (Fig. 7) [23]. The vulnerability outcome reveals that a total of four ranges of vulnerability indexes had been noted ranging from low in/on very high with vulnerability indexes $(2.133 \sim 4,>4 \sim 6,>6 \sim 8$ and $>8)$. The area of low vulnerability (vulnerability index $2.133 \sim 4$ ) occupies an area of $26 \mathrm{~km}^{2}$ or $2 \%$ of the whole 


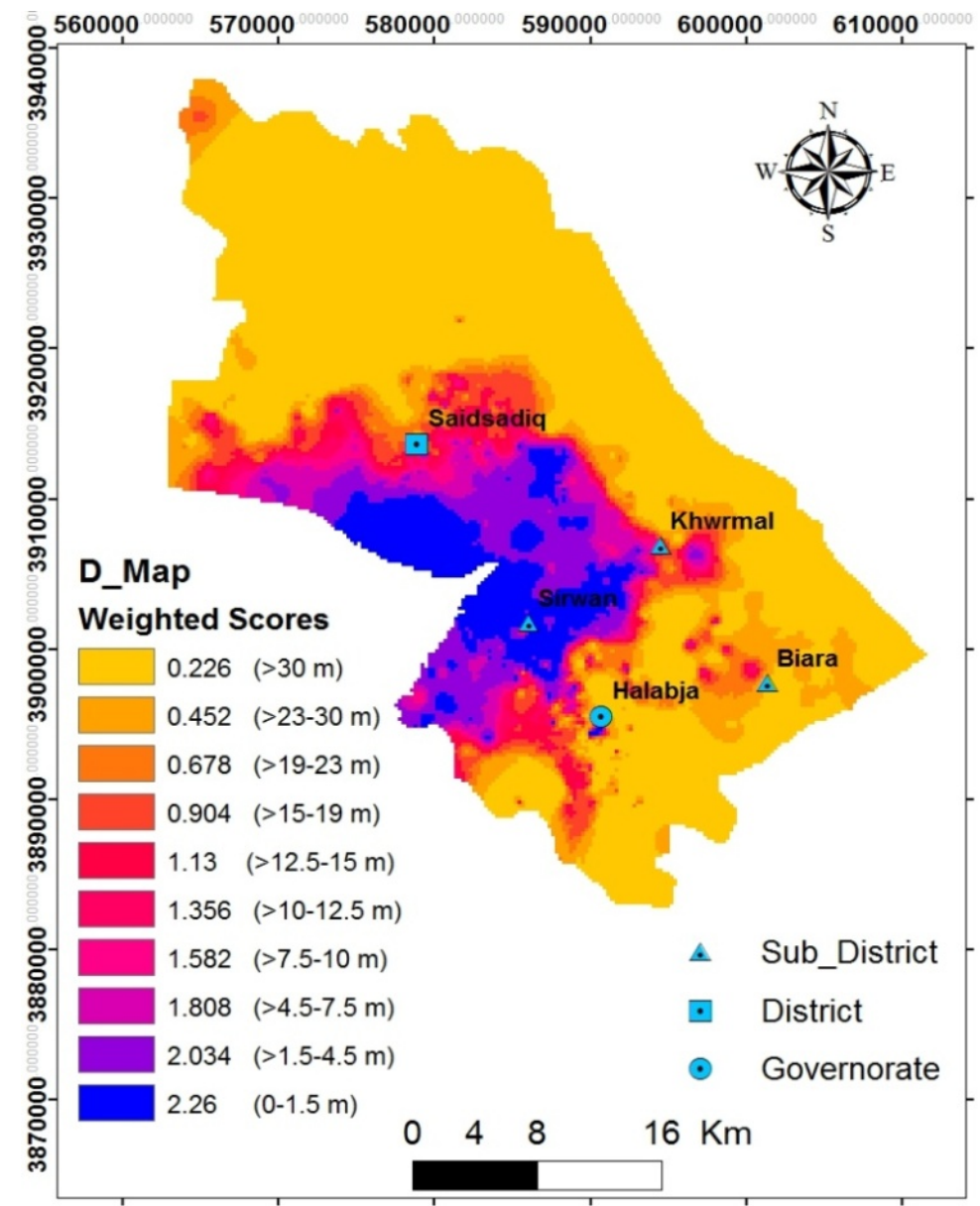

Fig. 5 Weighted scores of groundwater depth $(D)$.

area and located in the south west of the basin. Very high vulnerability class covered the central part of the basin of index value of $(>8)$ and an area of $(1 \%)$ or $13 \mathrm{~km}^{2}$. This area is characterized by high water table level and the presence of several springs with fractured limestone means such regions $(V, D$ and $A)$ have the highest values. The High vulnerability classes occupied the most of mountains area that is surrounding the basin and the central part of HSB. This vulnerability zone covered an area of $677 \mathrm{~km}^{2}$ or $53 \%$ of whole area. Finally, a medium vulnerability zone covered an area of $562 \mathrm{~km}^{2}$ or $44 \%$ of all studied area and it positioned in the southeast and northwest of the studied basin. The last two vulnerability classes (high and moderate) that occupied most of the studied basins refer to the exhaustive human activities, good water yield property of aquifers and fissured limestone and coarse-grain aquifers and vadose zone properties of these areas.

\subsection{Comparison of Both Models}

The VLDA map of the HSB (Fig. 7) shows high and moderate vulnerability throughout most of the basins. In terms of geological formation, this area is characterized by fissured carbonate rocks represented by Balamo, Kometan and Jurassic formations and fissured-karstic feature represented by Avroman Fn. and intergranular aquifer represented by alluvial deposits. The high level of vulnerability in these areas refers to the effectiveness of land use activities, suitability of aquifer media for transporting the contaminant and good aquifer properties in terms of yield and hydraulic conductivity. While based on the standard DRASTIC model in Fig. 2, the same area 
Table 6 Weighted scores of aquifer characteristics $(A)$.

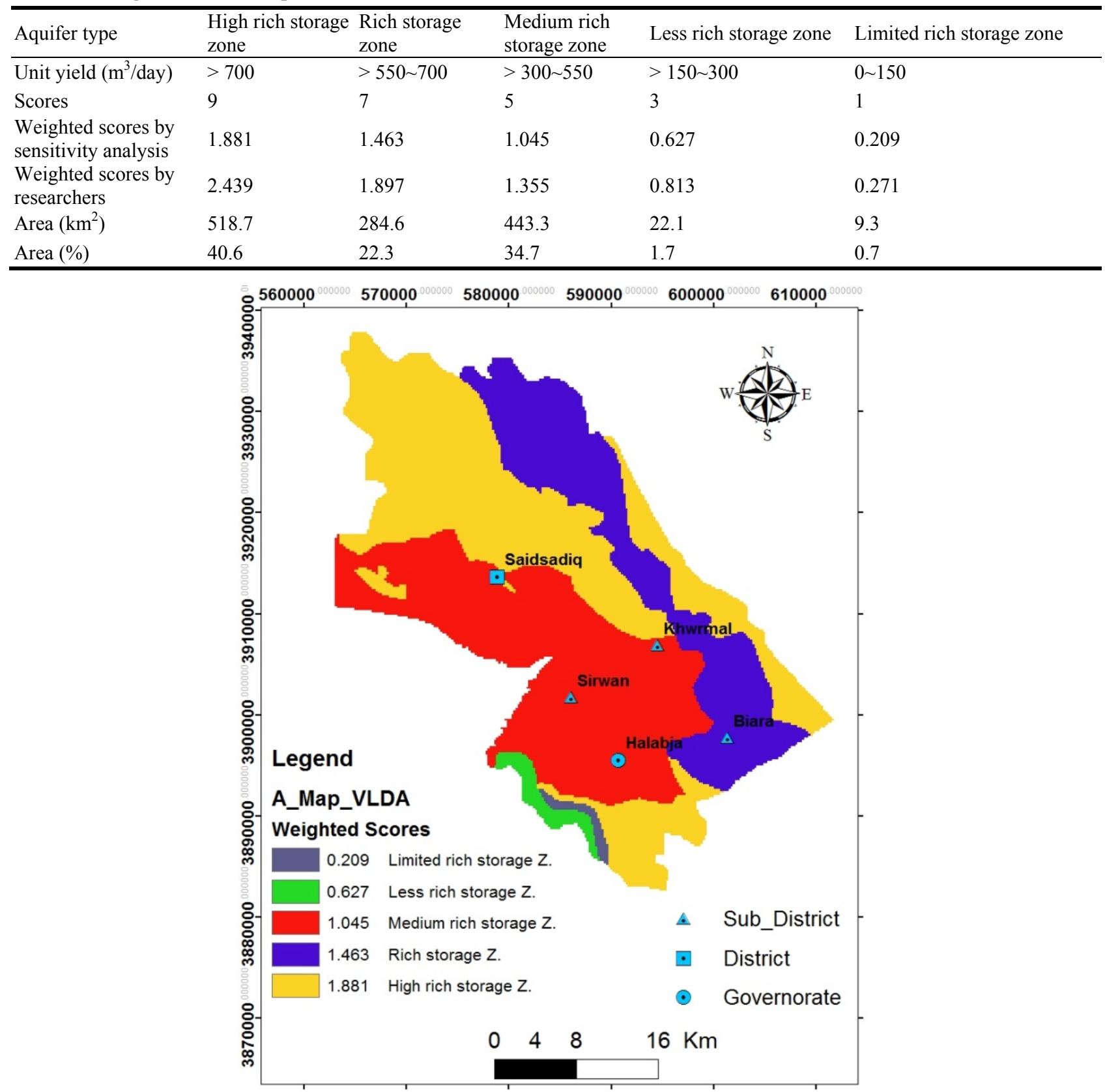

Fig. 6 Weighted scores of aquifer characteristics $(A)$.

is classified in to moderate vulnerability and very low vulnerability class as mentioned previously. In addition, low and very high classes come into view in the same area based on both methods in the central and south west parts of the basin.

\subsection{Validation of Both Models}

Each vulnerability map should be confirmed after construction in order to estimate the validity of the theoretical sympathetic of current hydrogeological conditions $[28,29]$. Several methods can be applied for the validation of vulnerability assessments; these include hydrographs, chemo-graphs and tracers (natural or artificial) [30]. In order to validate both applied models in HSB, nitrate concentration analysis has been selected. Nitrate as a pollution indicator can 
be helpful to recognize the evolution and changes of groundwater quality. In this particular studied case, the nitrate differences between two following seasons (dry and wet) were analyzed from 30 watering wells. The samples were collected and analyzed at the end of September 2014 for dry season and at the end of May 2015 for wet season. The selected wells for nitrate concentration measurement located nearly in all vulnerability zones in each model.
In relation to nitrate values for dry season (absence of rainfall for a long period) (Table 7), low nitrate levels were identified with concentration value ranging between 0 to just above $10 \mathrm{mg} / \mathrm{L}$. For DRASTIC vulnerability classes namely very low, low, moderate and high, the average of nitrate concentration of dry season was $<2,2 \sim 4,>10$ and $>$ $10 \mathrm{mg} / \mathrm{L}$, respectively (Fig. 8a). While for the wet season, the concentration significantly rose up $(0 \sim 20$,

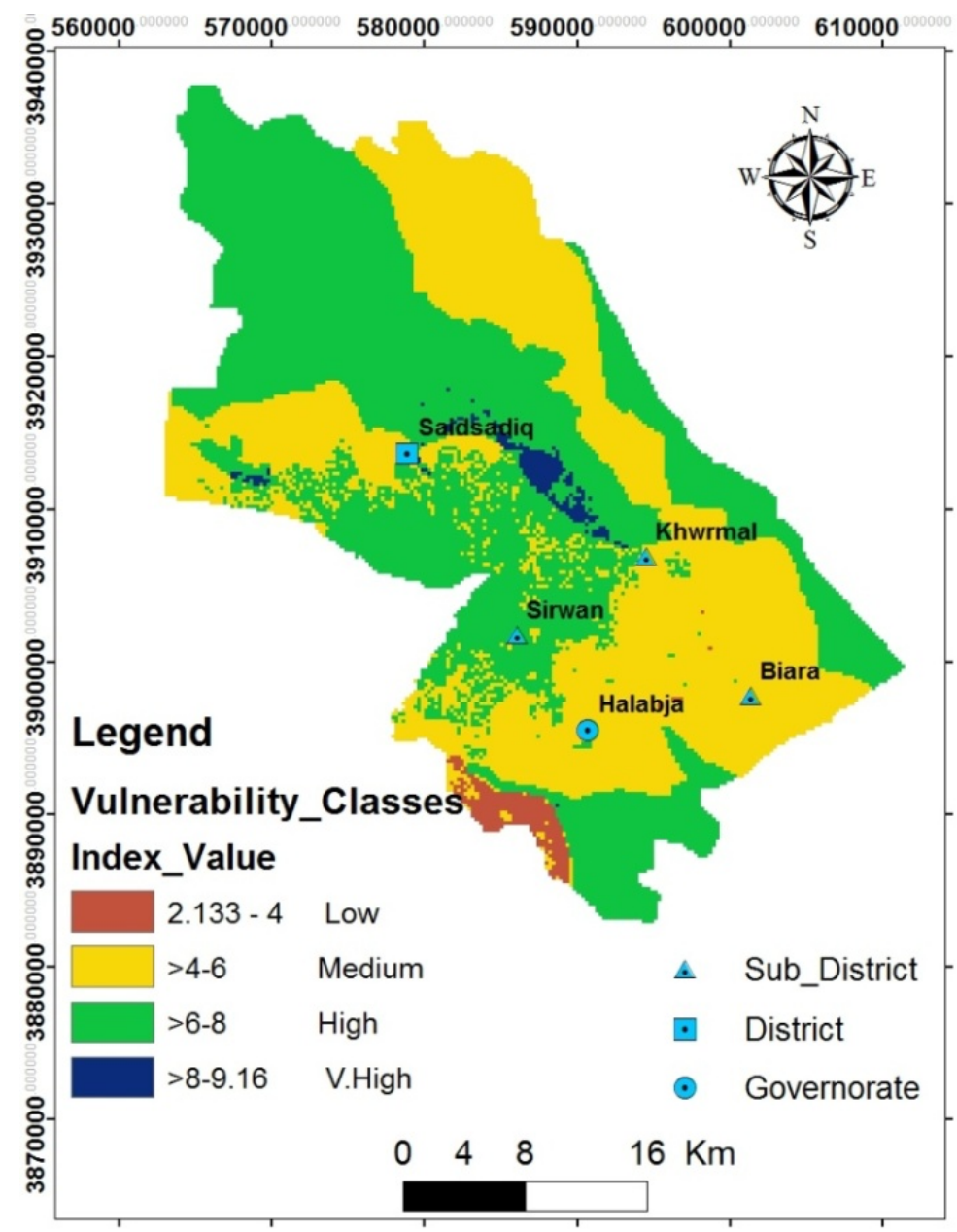

Fig. 7 VLDA vulnerability index map of HSB.

Table 7 Nitrate concentration in both dry and wet seasons in each vulnerability class.

\begin{tabular}{|c|c|c|c|c|c|}
\hline \multirow{2}{*}{$\begin{array}{l}\text { Standard DRASTIC } \\
\text { vulnerability classes }\end{array}$} & \multicolumn{2}{|c|}{ Nitrate concentration $(\mathrm{mg} / \mathrm{L})$} & \multirow{2}{*}{$\begin{array}{l}\text { VLDA vulnerability } \\
\text { classes }\end{array}$} & \multicolumn{2}{|c|}{ Nitrate concentration $(\mathrm{mg} / \mathrm{L})$} \\
\hline & Dry season & Wet Season & & Dry season & Wet season \\
\hline Very low & $<2$ & $0 \sim 20$ & Very low & - & - \\
\hline Low & $2 \sim 4$ & $20 \sim 30$ & Low & $2 \sim 4$ & $20 \sim 30$ \\
\hline Medium & $>10$ & $>30$ & Moderate & $>10$ & $>30$ \\
\hline \multirow{2}{*}{ High } & \multirow{2}{*}{$>10$} & \multirow{2}{*}{$>30$} & High & $>10$ & $>30$ \\
\hline & & & Very high & $>10$ & $>30$ \\
\hline
\end{tabular}




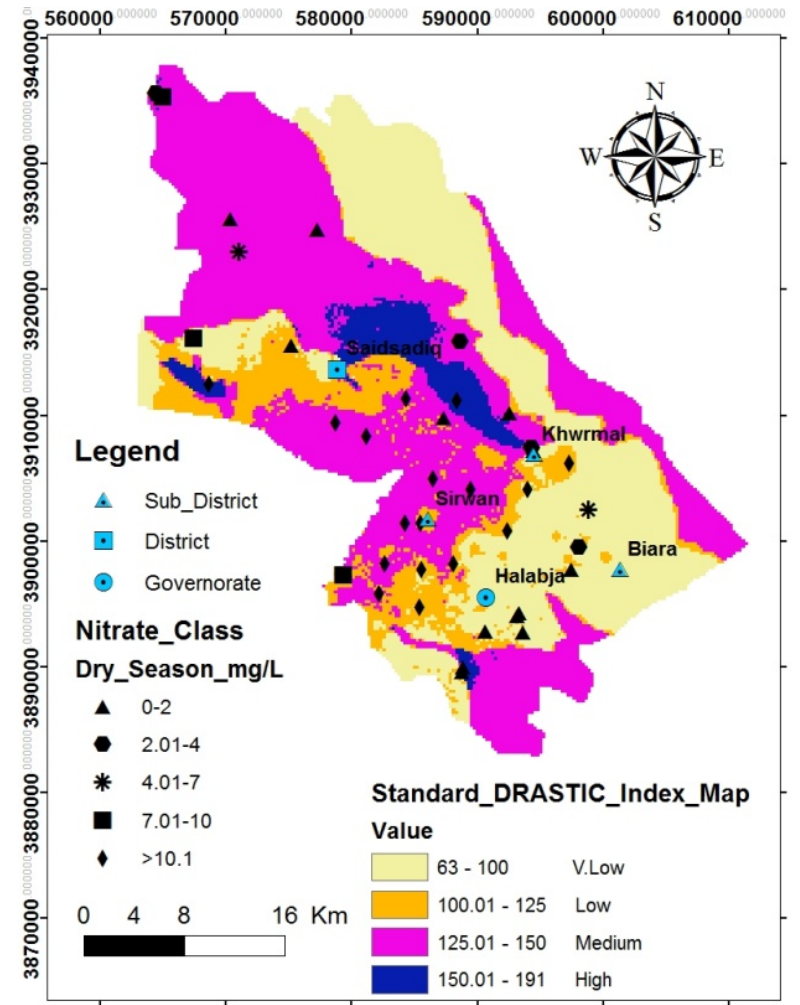

(a)

Fig. 8 Both models with nitrate concentration (dry season): $20 \sim 30,>30$ and $>30 \mathrm{mg} / \mathrm{L}$, respectively, (Fig. 9a)).This condition refers to several main factors such as rising up the water table in the wet season and vice versa for the dry season. Secondly, the impact on land uses activity is significant in wet season specifically using chemical contaminants (nitrate) for agriculture purpose. Finally, rainfall plays an important role to transport nitrate based on specific condition of aquifer characteristics. Consequently, these considerable variations in nitrate concentration of dry to wet seasons verify the suitability of applying this model in HSB.

Furthermore, nitrate concentration again was applied to verification for VLDA model. Vulnerability classes realized by this model in HSB were low, moderate, high and very high. The moderate and high classes covered a significant portion of the area of HSB. The average of nitrate concentration on dry season was $>10 \mathrm{mg} / \mathrm{L}$ for both classes, respectively (Fig. 8b). Whereas for wet season, the concentration considerably rose up ( $>30 \mathrm{mg} / \mathrm{L})$ for each class

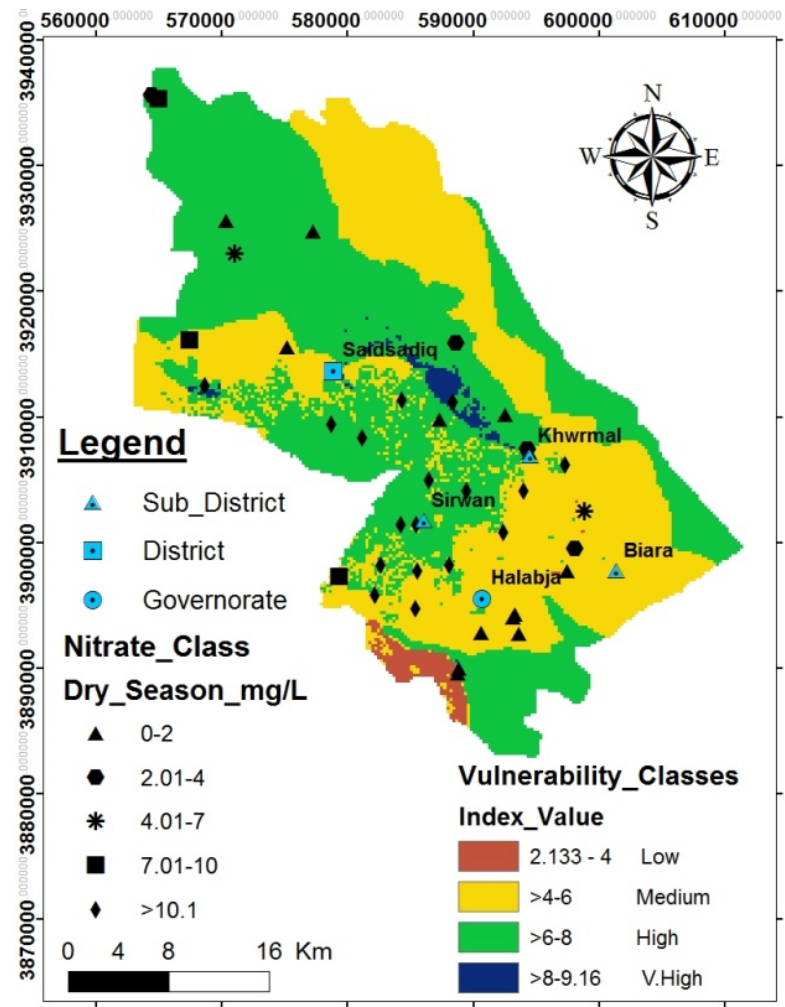

(b)

(a) DRASTIC model; (b) VLDA model.

(Fig. 9b). Therefore, these considerable variations in nitrate concentration on dry to wet seasons, verify the sensibility of the gradation and distribution of vulnerability levels acquired using the VLDA model. In addition, standard DRASTIC method needs to be modified based on different patterns that affect the vulnerability system in HSB and has not been declared in DRASTIC model.

\section{Conclusions}

Two different methods namely standard DRASTIC and VLDA were applied in GIS environment to assess the potential vulnerability of groundwater pollution in the HSB. The DRASTIC vulnerability indexes values ranged between 63 and 191 while the VLDA indexes to value ranged between 2.133 and 9.16. The higher index values of both DRASTIC and VLDA models mean higher vulnerability category.

The vulnerability classes are elucidated in Table 8. As it can be noted, both models clarify four vulnerability classes. DRASTIC model comprises very 


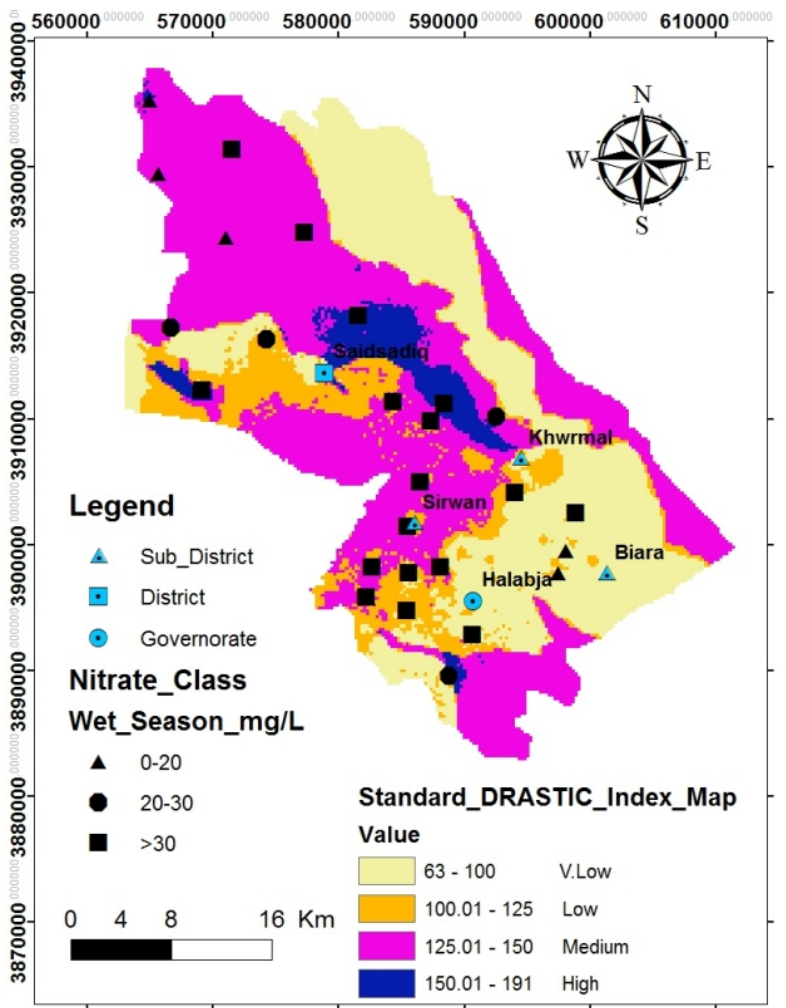

(a)

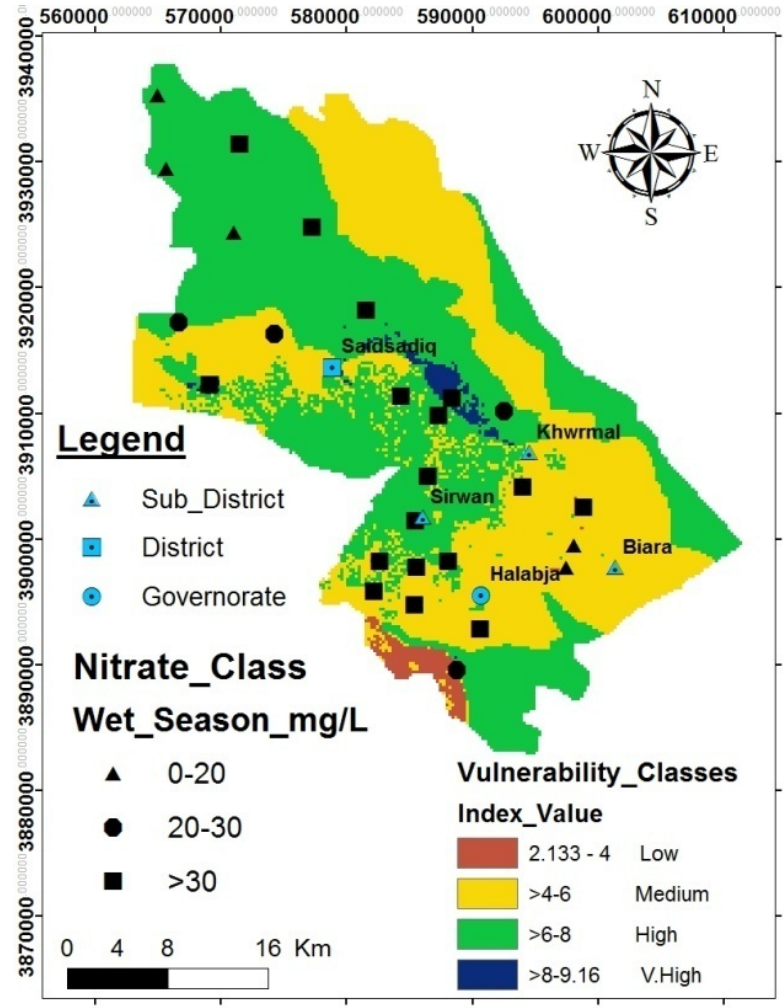

(b)

Fig. 9 Both models with nitrate concentration (wet season): (a) DRASTIC model; (b) VLDA model.

low to high, while VLDA model embraces low to very high. The moderate and very low vulnerable areas by DRASTIC model constitute $48 \%$ and $34 \%$, respectively, of the basin which is considered to be the most effectiveness classes; while for VLDA model, very low was not recorded and moderate occupied $44 \%$. Although low and high classes covered $13 \%$ and $5 \%$ for DRASTIC and $2 \%$ and $53 \%$ for VLDA models, respectively. Very high class was not recorded in DRASTIC model and by VLDA model, it was $1 \%$. The significant dissimilarity has been noted from both models. Therefore, validation of vulnerability maps for both models becomes obligatory. Nitrate as a pollution indicator from agricultural processes can be supportive to distinguish the evolution and changes of groundwater quality. In this particular study case, the nitrate differences between two following seasons (dry and wet) were analyzed from 30 watering wells. The result illustrates considerable variations in nitrate concentration on dry to wet seasons. So it can be concluded that groundwater in HSB is capable of receiving the contaminant due to suitability in geological and hydrogeological conditions. Based on this verification, Fig. 10 demonstrates that the degree and distribution of level of vulnerability acquired using the VLDA method is more sensible than that attained from standard DRASTIC methods. With increasing nitrate concentration the vulnerability rates increased as well, because land to use pattern is considered being one of the most effective factors of VLDA model and this parameter dose not included in DRASTIC model. So, the standard DRASTIC model is required to be modified based on the land uses Table 8 Result of DRASTIC index ratio for standard and modified maps.

\begin{tabular}{lll}
\hline Vulnerability class & DRASTIC rate (\%) & VLDA rate (\%) \\
\hline Very low & 34 & 0 \\
Low & 13 & 2 \\
Medium & 48 & 44 \\
High & 5 & 53 \\
Very high & 0 & 1 \\
\hline
\end{tabular}




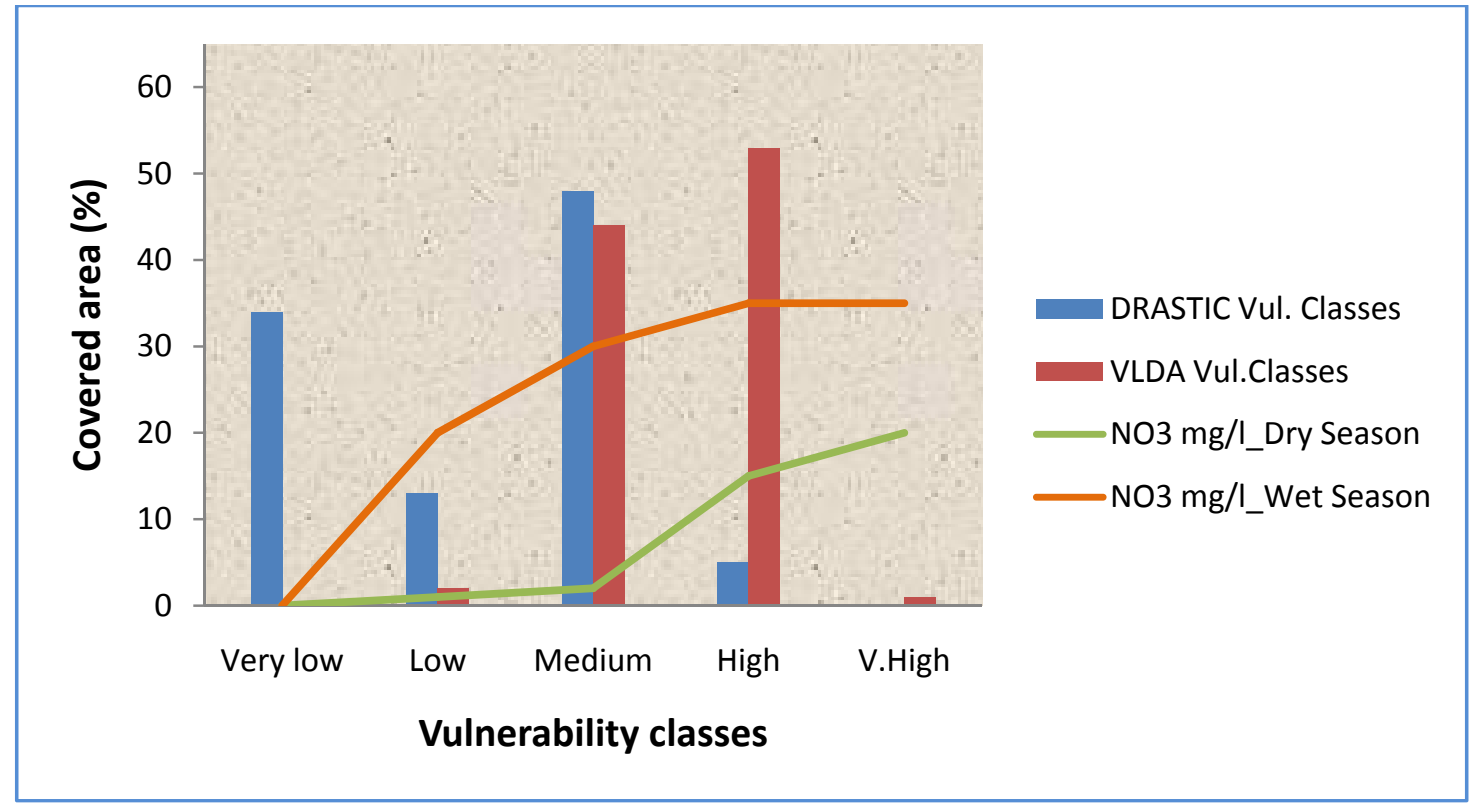

Fig. 10 Comparison of both models with nitrate concentration.

pattern so as to show the effect of man-made contamination on the groundwater.

\section{Acknowledgments}

The authors would like to thank D. Hussain Musa Hussain of Kufa University for his fruitful suggestions and discussions.

\section{References}

[1] Etienne, D. K., Boyssoro, H., Dibi, B., Mahaman, B., and Biemi, J. 2009. "Contribution Methods Intrinsic Vulnerability DRASTIC and GOD in The Study of Pollution by Nitrates in Bonoua Region (South-East of Ivory Coast)." Eur. J. Sci. Res. 31 (1): 157-71.

[2] Boufekane, A., and Saighi, O. 2010. "Use of GIS to Characterize the Vulnerability to Pollution-Application to the Alluvial Aquifer of the Wadi Nil (Jijel, Northeast Algeria)." International Network Environmental Management Conflicts 1: 267-74.

[3] Boufekane, A., and Saighi, O. 2013. "Assessment of Groundwater Pollution by Nitrates Using Intrinsic Vulnerability Methods: A Case Study of the Nil Valley Groundwater (Jijel, North-East Algeria)." Academic Journal 7 (19): 949-60.

[4] Attoui, B., Kherci, N., and Bousnoubra, H. 2012. "State of Vulnerability to Pollution of the Big Reservoirs of Groundwater in the Region of Annaba-Bouteldja (NE Algeria)." Geographia Technica. 2: 1-13.

[5] Abdullah, T. O., Ali, S. S., Al-Ansari, N. A., and
Knutsson, S. 2015a. "Effect of Agricultural Activities on Groundwater Vulnerability: Case Study of Halabja Saidsadiq Basin, Iraq." Journal of Environmental Hydrology 23 (10). Accessed October 10, 2015. http://www.hydroweb.com/protect/pubs/jeh/jeh2015/Ans ariGW.pdf.

[6] Huang, T., Pang, Z., and Edmunds, W. 2012. "Soil Profile Evolution Following Land-Use Change: Implications for Groundwater Quantity and Quality. Hydrol." Process 27 (8): 1238-52.

[7] Iraq. 2014. Statistical Directorate in Sulaimaniyah. Archive Department.

[8] Ali, S. S. 2007. "Geology and Hydrogeology of Sharazoor-Piramagroon basin in Sulaimani Area, Northeastern Iraq." Unpublished Ph.D. thesis, Faculty of Mining and Geology, University of Belgrade, Serbia.

[9] Buday, T., and Jassim, S. 1987. The Regional Geology of Iraq: Tectonis, Magmatism, and Metamorphism, edited by Kassab, I. I., and Abbas, M. J. Baghdad: State Organization for Minerals, Directorate General for Geological Survey and Mineral Investigations.

[10] Buday, T. 1980. Regional Geology of Iraq, edited by Kassab, I. I., and Jassim, S. Z. Vol. 1. Baghdad: State Organization for Minerals, Directorate General for Geological Survey and Mineral Investigations.

[11] Abdullah, T. O., Ali, S. S., Al-Ansari, N. A., and Knutsson, S. 2015b. "Groundwater Vulnerability Mapping Using Lineament Density on Standard DRASTIC Model: Case Study in Halabja Saidsadiq Basin, Kurdistan Region, Iraq." Engineering 7: 644-67. http://dx.doi.org/10.4236/eng.2015.710057. 
[12] Abdullah, T. O., Ali, S. S., and Al-Ansari, N. A. $2016 \mathrm{a}$. "Groundwater Assessment of Halabja Saidsadiq Basin, Kurdistan Region, NE of Iraq Using Vulnerability Mapping." Arabian Journal of Geosciences 9: 223. DOI 10.1007/s12517-015-2264-y. Accessed March 16, 2016. http://link.springer.com/article/10.1007/s12517-015-2264-y.

[13] Jassim, S. Z., and Guff, J. C. 2006. Geology of Iraq, edited by Jassim, D. G. Baghdad: State Organization for Minerals, Directorate General for Geological Survey and Mineral Investigations.

[14] Aller, L., Bennett, T., Lehr, J. H., Petty, R. H., and Hackett, G. 1987. DRASTIC: A Standardized System for Evaluating Groundwater Pollution Potential Using Hydrogeologic Setting. USEPA report 600/2-87/035, Robert S. Kerr Environmental Research Laboratory.

[15] Zhou, J., Li, Q., Guo, Y., Guo, X., Li, X., Zhoa, Y., and Jia, R. 2012. "VLDA Model and Its Application in Assessing Phreatic Groundwater Vulnerability: A Case Study of Phreatic Groundwater in the Plain Area of Yanji County, Xinjiang, China." Environmental Earth Science Journal 67: 1789-99.

[16] Zhou, J. L. 2009. "Groundwater Vulnerability Assessment Method of Inland Arid Areas." Ph.D. thesis, Graduate School of the Chinese Academy of Sciences, Beijing, China. (in Chinese).

[17] Ibe, K. M., and Nwankwor, G. I. 2001. "Assessment of Groundwater Vulnerability and Its Application to the Development of Protection Strategy for the Water-Supply Aquifer in Owerri, Southeastern Nigeria." Environ Monit Assess 67: 323-60 .

[18] Dixon, B. 2005. "Groundwater Vulnerability Mapping: A GIS and Fuzzy-Rule-Based Integrated Tool.” ApplGeogr 25: 327-47.

[19] Bukowski, P., Bromek, T., and Augustyniak, I. 2006. "Using the DRASTIC System to Assess the Vulnerability of Ground Water to Pollution in Mined Areas of the Upper Silesian Coal Basin.” Mine Water Environ 25: 15-22.

[20] Panagopoulos, G. P., Antonakos, A. K., and Lambrakis, N. J. 2006. "Optimization of the DRASTIC Method for Groundwater Vulnerability Assessment via the Use of Simple Statistical Methods and GIS." Hydrogeol J. 14: 894-911.

[21] Nobre, R. C. M., Filho, O. C. R., Mansur, W. J., Nobre, M. M. M., and Cosenza, C. A. N. 2007 "Groundwater
Vulnerability and Risk Mapping Using GIS, Modeling and a Fuzzy Logic Tool.” J ContamHydrol 94: 277-92

[22] Kourosh, M., Ramin, N., and Vahid, J. M. 2008. "Aquifer Vulnerability Assessment Using GIS and Fuzzy System: A Case Study of Tehran-Karaj Aquifer, Iran.” Environ Geol. 58 (2): 437-46. doi:10.1007/s00254- 008-1514-7.

[23] Abdullah, T. O., Ali, S. S., Al-Ansari, N. A., and Knutsson, S. 2016b. "Vulnerability of Groundwater to Pollution Using VLDA model in Halabja Saidsadiq Basin, Iraq." Presented at IWA Specialist Groundwater Conference, Belegrade, Serbia.

[24] Babiker, I. S., Mohamed, M. A., Hiyama, T., and Kato, K. 2005. "A GIS-based DRASTIC Model for Assessing Aquifer Vulnerability in Kakamigahara Heights, Gifu Prefecture, Central Japan." Science of the Total Environment 345 (1-3): 127-40.

[25] Javadi, S., Kavehkar, N., Mohammadi, K., Khodadi, A., and Kahawita, K. 2011. "Calibration DRASTIC Using Field Measurement, Sensitivity Analysis and Statistical Method to Assess Groundwater Vulnerability." Water International 36 (6): P719-32.

[26] Anderson, J. R., Hardy, E. E., Roach, J. T., Witmer, R. E. 1976. A Land Use And Land Cover Classification System for Use with Remote Sensor Data. Geological Survey Professional Paper 964. United States Government Printing Office.

[27] Hamamin, D. F. 2011. "Hydrogeological Assessment and Groundwater Vulnerability Map of Basara Basin, Sulaimani Governorate, Iraq, Kurdistan Region.” Unpublished Ph.D. thesis, College of Science, University of Sulaimani.

[28] Bruy'ere, S., Jeannin, P. Y., Dassargues, A., Goldscheider, N., Popescu, C., Sauter, M., et al. 2001. "Evaluation and Validation of Vulnerability Concepts Using a Physically Based Approach." Presented at the 7th Conference on Limestone Hydrology and Fissured Media.

[29] Perrin, J., Pochon, A., Jeannin, P. Y., and Zwahlen, F. 2004. "Vulnerability Assessment in Karstic Areas: Validation by Field Experiments." Environ Geol 46: 237-45.

[30] Zwahlen, F., ed. 2004. Vulnerability and Risk Mapping for the Protection of Carbonate (Karst) Aquifers. Final report (COST Action 620). Brussels: European Commission. 